\section{BJOS

Volume 17

2018

e18030

\title{
Changes in Head Posture, Hyoid Bone Position and Airway Dimensions After Orthognatic Surgery
}

Wanderson Roberto dos Santos Azevedo'; Christiane Cavalcante Feitoza ${ }^{2}$; Carlos Sanches Vargas Jr.; Karina Eiras Dela Coleta Pizzol ${ }^{4}$

\author{
1 Master in Orthodontics. United \\ Colleges of North of Minas - \\ FUNORTE, Maceió - AL, Brazil. \\ ${ }^{2} \mathrm{PhD}$ in Biothecnology. Federal \\ University of Alagoas - UFAL, \\ Arapiraca - AL, Brazil. \\ ${ }^{3}$ Master in Orthodontics. Araraquara \\ University - UNIARA, School \\ of Dentistry, Departament of \\ Orthodontics, Araraquara - SP, Brazil. \\ ${ }^{4} \mathrm{PhD}$ in Orthodontics. Araraquara \\ University - UNIARA, School \\ of Dentistry, Departament of \\ Orthodontics, Araraquara - SP, Brazil.
}

Corresponding author: Wanderson Roberto dos Santos Azevedo

wandersongrfc@hotmail.com

Received: October 08, 2017

Accepted: February 02, 2018
Abstract: Mandibular/bimaxillary advancement surgery is described as a potential means of increasing the oropharyngeal airspace, provided a significant improvement in breathing capacity. Aim: To evaluate postural changes suffered in the positioning of the head and the hyoid bone, dentofacial deformity patients undergoing orthognathic surgery with consequent dimensional changes of oropharyngeal airspace. Methods: We evaluated the archived records of patients with postoperative 6 months minimum, being used as criteria for selecting individuals with dental class II malocclusion and facial Pattern II, jaw or maxilomandibular deficiency, patients undergoing orthodontic-surgical treatment through mandibular advancement or of both bony bases, associated or not to genioplasty. Twenty-eight patients were part of the sample and were evaluated by means of lateral radiographs in lateral standard digitized, in three distinct periods: pre-operative, immediate, postoperative period and late postoperative period (minimum 6 months). 12 linear measures and two angular cephalometric analysis were used in this research. Results: With the surgery, there was an average of mandibular advancement $6.76 \mathrm{~mm}$, while remaining stable in the long-term follow-up period; the hyoid bone moved onward and upward, extending your movement in the post-operative. The cervical region presented minimal movement of the head extension in the immediate post operative with almost total returns the position of the head in the post-operative. The surgical movement of oropharyngeal air space was in the same direction of the mandibular movement, but to a lesser extent (1.88-2.76 mm). In the post-operative period was a late partial reduction of the diameter of the air space between $34-56 \%$ of gain, representing an apparent accommodation of this anatomical region soft tissue. Conclusion: Orthognathic surgery of mandibular advancement or bimaxillary promotes significant changes in aesthetics, in the position of the hyoid bone and upper airway dimensions, getting better quality of life to these patients. Keywords: posture; hyoid bone; oral surgical procedures. 


\section{Introduction}

Among the morphofunctional deviations which affect the population, Class II with skeletal involvement, also known as facial Pattern II, deserves special attention because of the significant changes it exerts in facial aesthetics and in masticatory and respiratory functions ${ }^{1,2}$.

Studies ${ }^{2-6}$ involving radiographic cephalometry in Pattern II individuals with mandibular deficiency and clockwise rotation have demonstrated that these patients frequently have higher anteroinferior facial height, Class II occlusion, height reduction of the mandibular branch, retraction of the base of the skull, frequent TMJ problems, narrow posterior air space, as well as an inferiorly positioned hyoid bone and maxillary retroposition.

The inadequate respiratory pattern in these individuals induces functional adaptations, promoting muscular imbalance of the face, postural changes such as parted lips and posterior head extension. The vital need to maintain the airspace pattern at the base of the tongue can explain the rotation in these Pattern II patients, who develop over the years a long face, due to mandibular retrusion, requiring orthognathic surgery for its correction?.

Mandibular advancement surgery is described as a potential means of increasing oropharyngeal airspace ${ }^{8}$, while, the airspace amplitude, obtained from it, is directly related to the amount of surgical advancement performed ${ }^{9,10}$. The first $10 \mathrm{~mm}$ of mandibular advancement tend to present a higher percentage of increase in the oropharyngeal air dimensions. For numbers above, the space continues to increase in size, but at a lower rate considering the amount of mandibular advancement. The position of the head and neck are also directly related to the dimensions of the pharyngeal air space acquired after maxillomandibular advancement surgery, as it has been demonstrated in clinical and experimental studies ${ }^{11,12}$.

As the studies referring to the morphofunctional alterations of facial-Pattern-II patients represent an open field in science, the present study aimed at examining the cephalometric relationship between the hyoid bone, mandible, skull and cervical spine, trying to establish a relationship between such variables and the size of the pharyngeal airspace before and after orthognathic surgery.

\section{Materials and Methods}

\section{Ethics Committee}

This study was submitted and approved by the Human Research Ethics Committee of the University of Araraquara (CEP) under number CAAE 32629314.3.0000.5383.

\section{Sample size}

This retrospective study was carried out by evaluating the cephalograms of 28 patients from the Centro de Pesquisa e Tratamento das Deformidades Bucofaciais (Center for Research and Treatment of Buccal Deformities - CEDEFACE, Araraquara_S.P., Brazil), 20 of which were female and 8 male, with an average 30 years of age. 


\section{Eligibility criteria}

A minimum postoperative period of 6 months, Class II and Standard II malocclusion due to mandibular deficiency, submitted to orthodontic-surgical treatment of mandibular or maxillomandibular advancement, associated or not to advanced genioplasty and / or anti-clockwise rotation of the occlusal plane. Initially, 686 medical records of individuals treated between 1997 and 2014 were evaluated, of which, according to inclusion and exclusion criteria, the medical records of 34 individuals were selected. During the sample selection, 6 cases were excluded because of any of the following factors: transverse maxillary discrepancy requiring surgical transverse intervention, presence of intercurrences during orthodontic-surgical treatment or need for a new surgical intervention, absence of complete documentation or of unsatisfactory quality, thus leaving a final sample of 28 individuals.

\section{Calibration}

The examiner was previously calibrated by repetition until the procedures were considered consistent by a second examiner. The intraclass correlation coefficient was always higher than 0.9. A pilot study was performed in order to minimize possible errors of the method.

\section{Study design}

The radiographs were evaluated in three distinct periods: preoperative ( $T 1$ ), up to 1 month before surgery; immediate postoperative period (T2), within 15 days after surgery; and late postoperative (T3), at least 6 months after surgery. For the evaluations at the proposed times, digital lateral cephalometric teleradiographs obtained from the same digital $\mathrm{X}$-ray imaging system (Vatech ${ }^{\circledR}$ PAx-400C, Korea) were used, on which the cephalometric analysis UNIARA, created by Radio Memory (Radio Memory®, Belo Horizonte_M.G., Brasil), based on the works of Coleta et al. ${ }^{4}$ and Dela Coleta et al. ${ }^{13}$, to meet the proposed objectives of the research. For its construction and greater position specificity, special tools were developed to help locate the 19 cephalometric landmarks used in the scientific work (Figure 1). Like the examiner, the method was previously tested in a pilot study.

A Horizontal Reference Line (LHR), drawn from Sella and at a seven-degree angle from S-N line and a perpendicular Vertical Reference Line (LVR) were used as reference for the quantification of the surgical movement, evaluation of the postural changes of the head and movement of the hyoid bone. Linear distances (millimeters) were measured from each point to the vertical and horizontal reference lines, thus obtaining two measurements for each cephalometric landmark (Figure 1). After the marking of the stitches, the pre and post-operative radiographs and tracings (immediate and late) were superimposed to check if the reference lines were coincident in all three surgical times. Based on the cephalometric tracings, it was possible to quantify the changes promoted by the surgery (T2-T1), as well as the stability of this movement (T3-T2). The cephalometric measurements used in the research are described in figure 1.

\section{Statistical analysis}

The data obtained in the study were divided into groups according to the type of surgery performed (maxillomandibular or mandibular) and also, according to the amount 


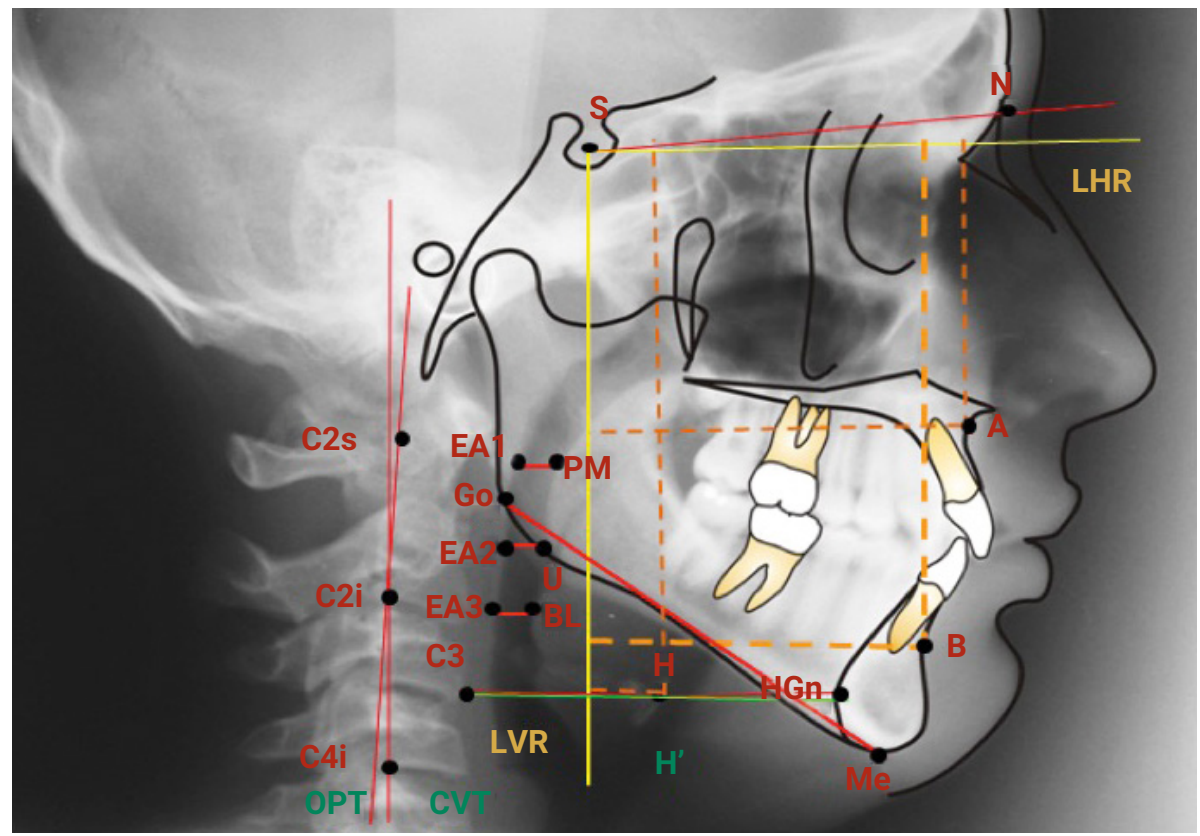

Figure 1. UNIARA cephalometric tracing, with cephalometric landmarks, reference lines and linear and angular cephalometric magnitudes.

of mandibular advancement ( $\leq 10 \mathrm{~mm}$ or $>10 \mathrm{~mm})$, for better interpretation of the data and comparison with findings of literature. The statistical analyzes used were the parametric Student's t-test for the data with normal distribution and the Pearson correlation coefficient to measure the degree of linear correlation between two variables.

\section{RESULTS}

All 28 patients in the sample underwent mandibular advancement (measured at point B), with a minimum movement of $2 \mathrm{~mm}$ and a maximum of $15 \mathrm{~mm}$. Approximately half of the patients (13) were also submitted to anti-clockwise rotation of the mandible and 9 received advancement / impaction mentoplasty as a complement to the mandibular advancement. The bimaxillary surgeries were performed in 9 patients, all characterized by the advancement, impaction and / or inclination of the palatal plane.

The values of the changes promoted by orthognathic surgery and long-term stability are described in table 1 (total sample); while in tables 2 and 3 , it is possible to visualize, in a comparative way, the surgical changes that occurred according to the type of surgery (maxillomandibular or mandibular) or the amount of movement executed ( $\leq 10 \mathrm{~mm}$ or $>10 \mathrm{~mm})$.

Pearson's correlation was applied to the airspace in the 3 areas measured and to the position of point $B$, the hyoid bone, the head and the neck produced low values for most variables. Table 4 shows Pearson's correlation according to the type of surgery performed and the amount of surgical movement. 
Table 1. Mean and standard deviation (SD) of the initial radiographs (T1), the surgical movement performed (T2-T1) and its stability (T3-T2)

\begin{tabular}{lcccccc}
\hline \multirow{2}{*}{ FACTORS } & \multicolumn{2}{c}{ T1 } & \multicolumn{2}{c}{ T2-T1 } & T3-T2 \\
\cline { 2 - 7 } & Mean & SD & Mean & SD & Mean & SD \\
\hline LINEAR $(\mathrm{mm})$ & & & & & \\
\hline A-LHR & 47.84 & 3.25 & -0.54 & 2.52 & -0.12 & 1.08 \\
\hline A-LVR & 71.54 & 6.39 & 0.7 & 2.79 & -0.42 & 1.36 \\
\hline B-LHR & 90.44 & 7.57 & 0.68 & 3.05 & -0.91 & 1.52 \\
\hline B-LVR & 61.59 & 8.47 & 6.76 & 4.81 & -0.62 & 2.28 \\
\hline H-LHR & 109.4 & 10.86 & -1.05 & 4.82 & -3.05 & 4.14 \\
\hline H-LVR & 15.88 & 7.75 & 2.48 & 6.7 & 0.98 & 4.24 \\
\hline H-H" & 9.11 & 6.56 & -2.14 & 4.75 & -1.26 & 4.04 \\
\hline C3-H & 34.98 & 4.13 & 1.02 & 2.1 & -0.83 & 2.21 \\
\hline H-RGn & 35.43 & 6.88 & 4.11 & 6.86 & -1.76 & 4.87 \\
\hline EAS & 10.28 & 3.11 & 1.88 & 2.66 & -1.06 & 2.15 \\
\hline EAM & 9.97 & 3.59 & 2.06 & 2.05 & -0.81 & 2.52 \\
\hline EAI & 9.94 & 3.78 & 2.76 & 2.32 & -0.95 & 2.64 \\
\hline ANGULAR $\left(^{\circ}\right)$ & & & & & & 2.54 \\
\hline SN.Go-Me & 37.1 & 7.79 & -1.56 & 3.43 & -0.18 & 2.54 \\
\hline OPT.CVT & 10.76 & 5.34 & 0.44 & 2.64 & -0.42 & 2.92 \\
\hline
\end{tabular}

Table 2. Mean, standard deviation (SD) and significance level (p) of surgical movement (T2-T1) and longterm stability (T3-T2), according to the type of surgery performed.

\begin{tabular}{|c|c|c|c|c|c|c|c|c|c|c|c|c|}
\hline \multirow{3}{*}{ FACTORS } & \multicolumn{6}{|c|}{ MAXILOMANDIBULAR SURGERY } & \multicolumn{5}{|c|}{ MANDIBULAR SURGERY } & \\
\hline & \multicolumn{3}{|c|}{$\mathrm{T} 2-\mathrm{T} 1$} & \multicolumn{3}{|c|}{ T3-T2 } & \multicolumn{3}{|c|}{ T2-T1 } & \multicolumn{3}{|c|}{ T3-T2 } \\
\hline & Mean & SD & $\mathrm{p}$ & Mean & SD & $\mathrm{p}$ & Mean & SD & $\mathrm{p}$ & Mean & SD & $\mathrm{p}$ \\
\hline A-LHR & -2.24 & 3.13 & & 0.40 & 1.34 & & 0.26 & 1.74 & & -0.37 & 0.87 & \\
\hline A-LVR & 0.98 & 2.63 & & -0.38 & 1.92 & & 0.57 & 2.93 & & -0.44 & 1.07 & \\
\hline B-LHR & -0.85 & 3.96 & & -0.48 & 0.92 & & 1.4 & 2.30 & & -1.11 & 1.72 & \\
\hline B-LVR & 10.89 & 4.84 & & -0.84 & 3.08 & & 4.81 & 3.43 & * & -0.52 & 1.88 & \\
\hline H-LHR & -0.87 & 5.96 & & -5.71 & 5.72 & & -1.13 & 4.37 & & -1.78 & 2.44 & \\
\hline H-LVR & 3.68 & 6.13 & & 1.23 & 4.64 & & 1.91 & 6.13 & & 0.86 & 4.64 & \\
\hline $\mathrm{H}-\mathrm{H}^{\prime \prime}$ & -1.00 & 3.97 & & -2.87 & 2.76 & & -2.68 & 3.97 & & -0.5 & 2.76 & \\
\hline $\mathrm{C} 3-\mathrm{H}$ & 1.08 & 1.86 & & -0.61 & 3.05 & & 0.99 & 1.86 & & -0.94 & 1.78 & \\
\hline $\mathrm{H}-\mathrm{RGn}$ & 7.79 & 5.06 & * & -3.40 & 4.75 & & 2.37 & 5.06 & & -0.97 & 4.75 & \\
\hline EAS & 1.86 & 2.27 & & 0.01 & 2.11 & & 1.89 & 2.27 & & -1.57 & 2.11 & \\
\hline EAM & 2.40 & 2.09 & & 0.43 & 2.71 & & 1.91 & 2.09 & & -1.4 & 2.71 & \\
\hline EAI & 3.52 & 2.25 & & -0.33 & 2.66 & & 2.41 & 2.25 & & -1.24 & 2.66 & \\
\hline SN.Go-Me & -4.43 & 2.72 & & 0.71 & 2.91 & & -0.2 & 2.72 & & -0.6 & 2.91 & \\
\hline OPT.CVT & 1.15 & 2.88 & & 0.20 & 3.12 & & 0.11 & 2.88 & & -0.71 & 3.12 & \\
\hline
\end{tabular}


Table 3. Mean, standard deviation (SD) and significance level (p) of surgical movement (T2-T1) and longterm stability (T3-T2), according to the amount of mandibular advancement.

\begin{tabular}{|c|c|c|c|c|c|c|c|c|c|c|c|c|}
\hline \multirow{3}{*}{ FACTORS } & \multicolumn{6}{|c|}{ ADVANCEMENT $\leq 10 \mathrm{~mm}$} & \multicolumn{6}{|c|}{ ADVANCEMENT $>10 \mathrm{~mm}$} \\
\hline & \multicolumn{3}{|c|}{$\mathrm{T} 2-\mathrm{T} 1$} & \multicolumn{3}{|c|}{ T3-T2 } & \multicolumn{3}{|c|}{ T2-T1 } & \multicolumn{3}{|c|}{ T3-T2 } \\
\hline & Mean & SD & $p$ & Mean & SD & $p$ & Mean & SD & $\mathrm{p}$ & Mean & SD & $\mathrm{p}$ \\
\hline A-LHR & -0.17 & 2.46 & & -0.19 & 1.12 & & -1.65 & 2.55 & & 0.09 & 2.02 & \\
\hline A-LVR & 0.46 & 2.75 & & -0.26 & 1.09 & & 1.45 & 3.00 & & -0.91 & 0.73 & \\
\hline B-LHR & 1.25 & 2.89 & & -0.97 & 1.72 & & -1.05 & 3.08 & & -0.71 & 2.93 & \\
\hline B-LVR & 4.51 & 2.67 & $\star$ & -0.09 & 1.80 & & 13.51 & 3.09 & & -2.22 & 4.54 & \\
\hline H-LHR & -1.68 & 4.55 & & -2.21 & 3.75 & & 0.84 & 5.48 & & -5.56 & 3.88 & \\
\hline H-LVR & 1.65 & 5.69 & & 1.04 & 4.44 & & 4.97 & 9.18 & & 0.79 & 4.51 & \\
\hline $\mathrm{H}-\mathrm{H}^{\prime \prime}$ & -2.85 & 3.94 & & -0.87 & 3.92 & & -0.02 & 6.54 & & -2.42 & 1.23 & \\
\hline $\mathrm{C} 3-\mathrm{H}$ & 0.81 & 2.08 & & -0.67 & 2.46 & & 1.64 & 2.20 & & -1.32 & 5.17 & \\
\hline $\mathrm{H}-\mathrm{RGn}$ & 2.59 & 5.24 & & -1.07 & 4.69 & & 8.69 & 9.37 & & -3.81 & 1.69 & \\
\hline EAS & 1.86 & 2.35 & & -1.22 & 2.30 & & 1.95 & 3.66 & & -0.58 & 1.32 & \\
\hline EAM & 1.87 & 2.21 & & -1.12 & 2.76 & & 2.64 & 1.44 & & 0.14 & 2.39 & \\
\hline EAI & 2.51 & 2.13 & * & -1.01 & 2.77 & & 3.51 & 2.85 & & -0.78 & 0.99 & \\
\hline SN.Go-Me & -0.67 & 3.22 & & -0.37 & 2.81 & & -4.8 & 1.72 & & 0.63 & 1.97 & \\
\hline OPT.CVT & 0.7 & 2.40 & & -0.35 & 3.21 & & -0.34 & 3.37 & & -0.63 & 0.00 & \\
\hline
\end{tabular}

Table 4. Pearson's correlation to airspace and position of the head, hyoid bone, mandibular advancement.

\begin{tabular}{|c|c|c|c|c|c|c|c|c|c|c|c|c|}
\hline \multirow{2}{*}{ FACTORS } & \multicolumn{6}{|c|}{ MAXILOMANDIBULAR SURGERY } & \multicolumn{6}{|c|}{ MANDIBULAR SURGERY } \\
\hline & EAS & & EAM & & EAI & & EAS & & EAM & & EAl & \\
\hline B-LHR & 0.48 & * & 0.33 & & 0.27 & & -0.23 & & 0.08 & & 0.27 & \\
\hline B-LVR & -0.23 & & 0.22 & & 0.16 & & -0.06 & & 0.10 & & 0.16 & \\
\hline H-LHR & -0.19 & & 0.17 & & 0.17 & & -0.14 & & 0.15 & & 0.17 & \\
\hline H-LVR & -0.27 & & -0.44 & * & -0.62 & * & -0.48 & * & -0.38 & & -0.62 & * \\
\hline OPT.CVT & 0.05 & & -0.17 & & 0.21 & & 0.07 & & 0.03 & & 0.21 & \\
\hline \multirow{2}{*}{ FACTORS } & \multicolumn{6}{|c|}{ ADVANCEMENT $\leq 10 \mathrm{~mm}$} & \multicolumn{6}{|c|}{ ADVANCEMENT $>10 \mathrm{~mm}$} \\
\hline & EAS & & EAM & & EAI & & EAS & & EAM & & EAI & \\
\hline B-LHR & 0.19 & & 0.20 & & -0.18 & & 0.48 & * & 0.17 & & 0.34 & * \\
\hline B-LVR & 0.05 & & 0.03 & & 0.02 & & -0.26 & & 0.33 & $\star$ & -0.02 & \\
\hline H-LHR & -0.04 & & 0.22 & & -0.14 & & -0.42 & * & -0.26 & & 0.10 & \\
\hline H-LVR & -0.34 & * & -0.52 & * & -0.47 & & -0.04 & & -0.27 & & -0.69 & ** \\
\hline OPT.CVT & 0.17 & & 0.17 & & 0.14 & & 0.12 & & 0.63 & $\star$ & 0.60 & * \\
\hline
\end{tabular}

* Weak to moderate correlation

** Strong correlation 


\section{DISCUSSION}

A variety of ways of assessing oropharyngeal airway changes as a result of orthognathic surgery, such as lateral cephalometry, computed tomography, polysomnography, and nasopharyngoscopy ${ }^{14,15}$ are described in relevant literature. In our study, we chose to measure the airspace through lateral normalized cephalometric radiographs, taken while patients were sitting and in the natural position of the head. This technique has the advantage of, conveniently, being part of the orthodontic documentation usually required for planning and post-surgical follow-up 4 . Some limitations were observed in the present study as the sample size, and post-surgical follow-up (minimum of 6 months). Although half of the sample had a follow-up of 12 months or more, in the case of airspace assessment. When evaluating the effects of orthognathic surgery on the airway in patients with obstructive sleep apnea, recurrence of the soft tissues of the airways during the first year has been observed, especially in advances fewer than $10 \mathrm{~mm}$. Thus, it would be interesting that the follow-up of all patients was greater than 12 months.

Another important factor is that linear analysis is based on craniometric points that undergo changes in anatomic location when observed in the preoperative and immediate postoperative periods. Likewise, the accommodation of soft tissues of the palate and tongue in the late postoperative period causes changes in the location of measurements of craniometric points. For this reason, in the cephalometric analysis of this study, the morphometric quantification of the airspace $a r e{ }^{16}$ was performed.

According to the literature ${ }^{3,8,17}$, maxillomandibular advancement movements promote a substantial increase of the airways in all dimensions, be it antero-posterior or lateromedial. In the present study, 9 patients underwent bimaxillary advancement surgery, with an average sagittal movement of $9.80 \mathrm{~mm}$ in the maxilla and $10.89 \mathrm{~mm}$ in the mandible. In these cases, there was a linearly quantified increase from cephalometry, $1.86 \mathrm{~mm}$ of airspace in the upper region, $2.40 \mathrm{~mm}$ in the middle region and $3.52 \mathrm{~mm}$ in the lower region, stable in the long run. The maxillo-mandibular advancement values achieved by the patients studied are compatible with other studies in the literature ${ }^{16,18}$. In the cases in which only the mandibular advancement was performed, which was the greater part of the sample studied ${ }^{19}$, the mean value found for point $B$ was lower compared to that of the maxillomandibular surgery group (4.81 mm, SD 3, 43mm), although both values are within those reported in the literature. This fact proves that the movements observed in the studied sample are comparable to the ones from studies already published, acting as a parameter for the evaluation of the modifications occurred in the oropharyngeal airspace.

Another movement capable of providing an increase in oropharyngeal airspace is the anticlockwise rotation of the occlusal plane, due to the lower and anterior positioning it provides to the soft tissues of the palate, promoting an increase in space for the tongue that is now more anterior ${ }^{9,16,18,19}$. Keeping the supra-hyoid muscles attached to the anterior region of the mandible promotes an anterior tension of the tongue and hyoid bone, pulling them forward, and consequently, significantly increasing the pharyngeal airspace. In the present study, 13 patients were submitted to anti-clockwise rotation of the mandible, and 9 of them also received advancement / impaction 
mentoplasty both as a complement to the mandibular advancement and as an additional movement. In these patients, the results of oropharyngeal airway gain were slightly higher than in the others, which reinforces the importance of this movement to increase the span of the upper airways.

Soft tissue edema is a factor that should be considered when assessing air space and head posture, especially in the immediate postoperative period of bimaxillary advancement surgery. This fact may justify the small average gain of oropharyngeal airspace in our sample, which ranged from $27.81 \%$ to $40.82 \%$ of the mandibular advancement, since 8 patients presented some reduction of the initial air space in one of the measured areas (upper, middle or lower) in the immediate postoperative period. Carvalho ${ }^{16}$ also observed this event in his sample $(n=20)$, with a reduction in both area and volume of airspace of four patients in the immediate postoperative period but who had a substantial gain in the late postoperative period. These findings corroborate the study by Coleta et al. ${ }^{4}$, who obtained an increase of $28 \%$ in the upper air space related to mandibular advancement. Apparently, airway edema may have camouflaged the actual gain of airspace in the immediate postoperative period in such cases.

In addition to postoperative soft tissue edema, the size of the airspace is also subject to the influence of the type and the amplitude of the surgical movement performed. Authors such as Li et al..$^{20}$ considered that for a $10 \mathrm{~mm}$ skeletal advancement a $5 \mathrm{~mm}$ gain was obtained in the oropharyngeal space in its anteroposterior diameter, predicting a relation between the movement of the bone bases and the linear airway gain of about 2: 1. Although the present study recorded an average linear airway gain of less than $50 \%$ of the surgical movement performed, when the sample was divided into two groups, according to the amount of mandibular advancement performed, different proportions of airspace gain became evident. In the group where mandibular advancement was $>10 \mathrm{~mm}$ (mean value of $13.51 \mathrm{~mm}$ ), the percentage of airspace increase in the three areas analyzed ranged from $14.43 \%$ to $25.98 \%$ for the measure obtained for B-LVR. In the group with mandibular advancement $\leq 10 \mathrm{~mm}$ (mean value of $4.51 \mathrm{~mm}$ ), the linear airspace gain varied from $41.24 \%$ to $55.65 \%$ of the mandibular surgical movement. In both groups, there was a substantial reduction in airspace in the 3 points measured in the late postoperative period. This difference between the proportions of the linear gain of the oropharyngeal airway observed between the two groups of the present study can be justified by the work of Reiche-Fischel and Wolford ${ }^{21}$, in which the oropharyngeal space changes of 72 patients with mandibular advancement were evaluated. In this study, the authors demonstrated that there was a higher percentage of airspace size gain for the first $10 \mathrm{~mm}$ of mandibular advancement (66\%). For advancements greater than $10 \mathrm{~mm}$, the air space continues to increase in size, but at a lower rate relative to the amount of mandibular advancement (between 10 and $15 \mathrm{~mm}$ of mandibular advancement, the air space increased $56 \%$ and for advances $>15 \mathrm{~mm}$ the space gain was $41 \%$ ). Considering that the normal size of the upper airways is $11 \pm 2 \mathrm{~mm}^{22}$ when measured on lateral radiography, our results showed mean values for airspace always higher than $12 \mathrm{~mm}$ in the immediate postoperative period, stabilizing above $11 \mathrm{~mm}$ in the late postoperative period, within the limits of normality.

Another area that plays an important role in the maintenance of oropharyngeal airspace and that is influenced by the surgical movement of the mandible is the hyoid bone $e^{7,12,14,23,24}$. 
The antero-posterior position of the hyoid bone is determined by the joint action of the muscles that are attached to the structures above and below it and by the resistance offered by the elastic membranes of the larynx and trachea, which forces it towards a return to, almost, its original position after a certain postoperative period ${ }^{12,14,23,25}$. The vast majority of studies describe changes in the position of the hyoid bone and in the size of the pharyngeal space 1-2 years after surgery $7,12,13,23-25$. Contrary to these findings, we observed a forward and upward movement of the hyoid bone following the surgical movement of the mandible. Although the distances between the $\mathrm{H}-\mathrm{C} 3$ and $\mathrm{H}-\mathrm{RG}$ n points were reduced in the late postoperative period, the linear distance of the hyoid bone in relation to the vertical and horizontal reference lines clearly showed an enhancement of the movement obtained in the hyoid bone soon after the surgery without relapse.

The relation between the position of the hyoid bone and the posture of the head has also been studied in some scientific articles, in which it was verified that the position of the head promotes antero-posterior adaptation of the hyoid bone and interferes in the pre and post-surgical size of airspace 11,26,27.

Patients with long face and facial pattern II tend to exhibit an extended head posture as a way to improve respiratory capacity. However, after surgery, there is a strong tendency for the head to flex, after most surgical procedures, acquiring a more centralized position. The cervical skull position acquired after surgery is influenced by supra-hyoid post-surgical muscle tension, by the direction and distance of the surgical movement, and by changes in the upper airways. The angle formed by the CVT and OPT lines, used to observe the changes in the cervical region resulting from the surgery, showed a minimal movement of cervical flexion in the immediate postoperative period $\left(0.44^{\circ}\right)$, directing the head upward, with an almost complete return, to the previous position, of the head in the late postoperative period $\left(-0.42^{\circ}\right.$ of cervical extension). Coleta et al. ${ }^{4}$ observed that patients flexed their heads after surgery $\left(5.6^{\circ}\right)$ and extended it $1.8^{\circ}$ during long-term follow-up. Other authors have reported a $0.65^{\circ}$ to $3.4^{\circ}$ of flexion of the head after mandibular advancement surgery 24,28 . The lack of standardization in the positioning of the head and neck during X-ray imaging may justify the wide variety of values obtained for the cervical skull region in different scientific studies ${ }^{4}$.

Although most of the changes observed in the present study were similar to those reported in the literature, few variables showed statistically significant changes, just as the correlations observed between airspace and other areas were not strong, with the exception of H-LVR and IEA (>10 mm). This can probably be explained by the fact that, although the sample had a reasonable number of individuals, when divided into groups, they became relatively low in number for statistical analysis, interfering with the results. Thus, it would be prudent to continue the study increasing the size of the sample for greater fidelity of the statistical data.

In conclusion, orthognathic surgery of mandibular / bimaxillary advancement promoted favorable changes in position of the hyoid bone and in the dimensions of the upper airways. The upper airways showed an increase in their dimensions after surgery, and this gain was proportionally greater in cases of bimaxillary surgery and mandibular advancement of less than $10 \mathrm{~mm}$. Statistical analysis showed, in most cases, little correlation between changes in the mandible, hyoid bone and / or head with the increase in oropharynx airspace. 


\section{REFERENCES}

1. Pizzol KEDC, Barbeiro RH, Coleta RD, Marcantonio E. [Evaluation of occlusal plane alteration in Orthognathic Surgeries combined with rigid internal fixation in Class II skeletal facial standard patients]. Rev Dental Press Ortod Ortop Facial. 2006;11(4):104-17. Portuguese.

2. Raffani M, Pisani C. Clinical and cone-beam computed tomography evaluation of the three-dimensional increase in pharyngeal airway space following maxilla-mandibular rotation-advancement for Class II - correction in patients without sleep apnoea (OSA). J Craniomaxillofac Surg. 2013 Oct;41(7):552-7. doi: 10.1016/j.jcms.2012.11.022.

3. Ronchi P, Cinquini V, Ambrosoli A, Caprioglio A. Maxillomandibular advancement in obstructive sleep apnea syndrome patients: a restrospective study on the sagittal cephalometric variables. J Oral Maxillofac Res. 2013 Jul 1;4(2):e5. doi: 10.5037/jomr.2013.4205.

4. Coleta KED, Wolford LM, Gonçalves JR, Santos-Pinto A, Pinto LP, Cassano DS, et al. Maxillo-Mandibular Counter-Clockwise Rotation and Mandibular Advancement with TMJ Concepts Total Joint Prostheses: Part II Airway Changes and Stability. Int J Oral Maxillofac Surg. 2009 Mar;38(3):228-35. doi: 10.1016/j.ijom.2008.11.021.

5. Mishima K, Yamada T, Sugahara T. Evaluation of respiratory status and mandibular movement after total temporomandibular joint replacement in patients with rheumatoid arthritis. Int J Oral Maxillofac Surg. 2003 Jun;32(3):275-9.

6. Lee YJ, Park JT, Cha JY. Perioral soft tisuue evaluation of skeletal Class II Division 1: A lateral cephalometric study. Am J Orthod Dentofacial Orthop. 2015 Sep;148(3):405-13. doi: 10.1016/j.ajodo.2015.03.033.

7. Opdebeeck MD, Bell WH, Eisenfeld J, Mishelevich D. Comparative study between the SFS and LFS rotation as a possible morphogenic mechanism. Am J Orthod. 1978 Nov;74(5):509-21.

8. Gokce SM, Gorgulu S, Gokce HS, Bengi AO, Karacayli U, Ors F. Evaluation of pharyngeal airway space changes after bimaxillary orthognathic surgery with a 3-dimensional simulation and modeling program. Am J Orthod Dentofacial Orthop. 2014 Oct;146(4):477-92. doi: 10.1016/j.ajodo.2014.06.017.

9. Mehra P, Downie M, Pita M, Wolford LM. Pharyngeal airway space changes after counterclockwise rotation of the maxillomandibular complex. Am J Orthod Dentofacial Orthop. 2001 Aug;120(2):154-9.

10. Islam S, Uwadiae, Ormiston IW. Orthognathic surgery in the management of obstructive sleep apnoea: experience from maxillofacial surgery unit in the United Kingdom. Br J Oral Maxillofac Surg. 2014 Jul;52(6):496-500. doi: 10.1016/j.bjoms.2014.04.002

11. Muto T, Yamazaki A, Takeda S, Kawakami J, Tsuji Y, Shibata T, et al. Relationship between the pharyngeal airway space and craniofacial morphology, taking into account head posture. Int J Oral Maxillofac Surg. 2006 Feb;35(2):132-6.

12. Jiang C, Yi Y, Jiang C, Fang S, Wang J. Pharyngeal airway space and hyoid bone positioning after different orthognathic surgeries in skeletal Class II patients. J Oral Maxillofac Surg. 2017 Jul;75(7):1482-1490. doi: 10.1016/j.joms.2017.02.021.

13. Dela Coleta KE, Wolford LM, Gonçalves JR, Santos-Pinto A, Pinto LP, Cassano DS. Maxillo-mandibular counterclockwise rotation and mandibular advancement with TMJ Concepts total joint prostheses: part I-skeletal and dental stability. Int J Oral Maxillofac Surg. 2009 Feb;38(2):126-38. doi: 10.1016/j.ijom.2008.11.024.

14. Riepponen A, Myllykangas R, Savolainen J, Kilpeläinen P, Kellokoski J, Pahkala R. Changes in posterior airway space and hyoid bone position after surgical mandibular advancement. Acta Odontol Scand. 2017 Jan;75(1):73-78. doi: 10.1080/00016357.2016.1252851.

15. Bianchi FA, Gerbino G, Corsico M, Schellino E, Barla N, Verzè L, et al. Soft, hard-tissues and pharyngeal airway volume changes following maxillomandibular transverse osteodistraction: Computed tomography and three-dimensionsional laser scanner evaluation. J Craniomaxillofac Surg. 2017 Jan;45(1):47-55. doi: 10.1016/j.jcms.2016.10.005. 
16. Carvalho ACGS. [Cephalometric and tridimensional avaliation of posterior airway space after maxillomandibular advancement] [tese]. Araçatuba: Faculdade de Odontologia, Universidade Estadual Paulista; 2011. Portuguese.

17. Zhao X, Liu Y, Gao Y. Three-dimensional upper-airway changes associated with various amounts of mandibular advancement in awake apnea patients. Am J Orthod Dentofacial Orthop. 2008 May;133(5):661-8. doi: 10.1016/j.ajodo.2006.06.024.

18. Gonçalves JR, Buschang PH, Gonçalves DG, Wolford LM. Postsurgical stability of oropharyngeal airway changes following counter-clockwise maxillo-mandibular advancement surgery. J Oral Maxillofac Surg. 2006 May;64(5):755-62.

19. Wei S, ZhangY, Guo X, Yu W, Wang M, Yao K et al. Counterclockwise maxillomandibular advancement: a choice for Chinese patients with severe obstrutive sleep apnea. Sleep Breath. 2017 Dec;21(4):853-860. doi: 10.1007/s11325-017-1484-7.

20. Li KK, Powel NB, Riley RW, Troell RJ, Guilleminault C. Long term results of maxillomandibular advancement surgery. Sleep Breath. 2000;4(3):137-140.

21. Reiche-Fischel O, Wolford LM. Posterior airway space changes after double jaw surgery with counter-clockwise rotation. AAOMS 78th Annual Meeting and Scientific Sessions. J Oral Maxillofac Surg 1996;54:96.

22. Riley RW, Powell NB, Guilleminault C. Obstructive sleep apnea syndrome: a surgical protocol for dynamic airway reconstruction. J Oral Maxillofac Surg. 1993 Jul;51(7):742-7; discussion 748-9.

23. Chung DH, Hatch JP, Dolce C, Van Sickels JE, Bays RA, Rugh JD. Positional change of the hyoid bone after bilateral sagittal split osteotomy with rigid and wire fixation. Am J Orthod Dentofacial Orthop. 2001 Apr;119(4):382-9.

24. Gale A, Kilpeläinen PV, Laine-Alava MT. Hyoid bone position after surgical mandibular advancement. Eur J Orthod. 2001 Dec;23(6):695-701.

25. Wessberg GA, Schendel SA, Epker BN. The role of suprahyoid myotomy in surgical advancement of the mandible via sagittal split ramus osteotomies. J Oral Maxillofac Surg. 1982 May;40(5):273-7.

26. Winnberg A, Pancherz H,Westesson PL. Head posture and hyomandibular function in man. A synchronized electromyographic and videofluorographic study of the open-close-clench cycle. Am J Orthod Dentofacial Orthop. 1988 Nov;94(5):393-404.

27. Hedayati Z, Paknahad M, Zorriasatine F. Comparison of natural head position in different anteroposterior malocclusions. J Dent (Tehran). 2013 May;10(3):210-20.

28. Phillips C, Snow MD, Turvey TA, Proffit WR. The effect of orthognathic surgery on head posture. Eur J Orthod. 1991 Oct;13(5):397-403. 